\title{
Evaluation of Social Sustainability in Residential Neighborhoods
}

\author{
Zahra Mohammadzadeh Neilagh ${ }^{1}$, Mitra Ghafourian ${ }^{2}$
}

\begin{abstract}
As the consequence of rapid urbanization, in most metropolitan areas, especially in developing countries, due to lack of attachment to the residential neighborhoods, and loss of the inhabitant's concentration toward their surrounding environment, most of the neighborhoods are gradually eroded both physically and socially. Regarding different aspects of social sustainability and current urban planning standards for residential neighborhoods, it seems that these aspects shall be combined together to produce socially sustainable neighborhoods in every zone of the city and lead to a widely experienced improvement of local identity. In this paper, the selected area included residential neighborhoods in district 12 of Tehran municipality allowing us to study different aspects of social sustainability and survey its indices in a mid-income social class that is relatively uniform and benefit from common services.
\end{abstract}

Keywords: attachment, neighborhood, social sustainability, urbanization.

\section{Introduction}

The increasing concern over environmental degradation and loss of social interaction in urban residential neighborhoods have resulted in a great deal of research revealing significance of social sustainability in human settlements. The significance of social sustainability, is now commonly involved in the all aspects of life in urban communities. Consequently, new kinds of public spaces and meeting forums are now being necessary in residential neighborhoods of towns and cities, which can be an important social resource for interaction of urban inhabitants. However, the success of this social space in residential neighborhoods is still emerging and disputable since the success of a particular space in an urban area is not solely in the hands of the architects, urban designers or town planners; it also relies on people living in the neighborhood, using and managing the spaces and places.

Residents of older neighborhoods in Tehran are facing further diminish in the sense of social attachment to place and weakens the depth of meaning and diversity of place experience. Regarding the dynamics of place and place meaning, there is an emergent need to understand the psychological aspects in the changing context of urban areas influenced by globalized culture and built form (Altman \& Low, 1992). With the lack of attachment to the residential neighborhoods in Tehran, and loss of the inhabitant's concentration toward their surrounding environment, the neighborhood environment is being gradually decayed both physically and socially, and these consequences later invade into the interior environment of the home affecting the quality of life. 
This paper discusses the nature of social sustainability indices and their significance in the creation of a true "sense of place", which plays a fundamental and key role in the success of sustainable residential environments. The concept of social sustainability and its attributed topics are mostly rooted in multiple fields of study at several theoretical and empirical levels; these include phenomenology, psychology, sociology, geography, etc. As a result, the sense of place and sustainability become weak and affect people's feelings and perception of the area because of poorly informed neighborhoods or those motivated by purely commercial motives.

\section{Literature Review}

According to the established principles of sustainability, social sustainability has a strong relationship with ecological and economic sustainability of the society. This relationship is important in the process of improving the quality of life within urban communities.

Littig and Griebler (2005) have described that the theory of social sustainability is actually based on the concepts of demands, needs and income of a society. It is the human activities that are applied to fulfill human needs by considering the interdependence process between society and nature, and the focus is on the man and nature relationship on human action. It is a productive interaction which influences the stability of all natural resources. The Model of Social Sustainability developed by WACOSS (2002) revealed five main principles of social sustainability including equity, diversity, quality of life, interconnectedness, and democracy and governance for urban areas.

In the field of phenomenology, other researchers like Heidegger (1889-1976) have proposed that dwelling expresses a meaningful relationship between man and the surrounding environment; a relationship that grows from one's efforts to gain identity, which then, can lead to an emotional attachment to a place or area (Heidegger, 1962). Lynch (1979) has focused on the subject and has proposed that a clear subjective image of an urban place is the main attribute of the identity of that place, and Schulz and Relf have examined deep emotional and perceptual features and links between man and living environment (Habibi, 2008). There are three broad, interrelated components that compose a place and give meaning to it: the physical setting, the individual's internal psychological and social processes, and activities that have been undertaken (Relph, 1976; Stedman, 2003).

Nowadays, what is discussed under the title of social sustainability or sometimes social attachment in urban studies arise from an interdisciplinary social approach to urbanization and urban life. In fact, after the top styles which had been developed in recent decades after decline of modernism, attention to the human-oriented urbanism as the production which could meet human needs in different dimensions, led to the formation of approaches in urban studies that are known as social approaches.

Colantino et al (2009) have defined social sustainability as how individuals, communities and societies can live together and set out to achieve the common social objectives of development patterns which they have chosen for themselves and their society taking into account the physical as well as environmental boundaries of their places.

Social sustainability has always been studied and researched quite broadly, and so has 
been approached or defined in a variety of ways. There are different concepts used to name people's link and relations with the surrounding environment and places: attachment, social sustainability, livability, life satisfaction, spatial identity, place dependence, sense of place, urban attachment and sustainability or sense of community, each of them bear a somewhat different framework and meaning, although what exactly is their real differences is not clear yet. Most part of studies on social sustainability cab be sorted and classified into three contexts including personal context, natural environment context and community context.

The personal context includes topics like place identity, place dependence, attachment and rootedness. The natural environment context includes connectedness to nature, environmental identity and affinity to nature. The community context includes neighborhood sustainability, belongingness and familiarity (Raymond et al., 2010). Nature bonding may not be applicable for the measurement of social sustainability in urban settings, but it is relevant to natural and rural land-use contexts, which is the focus of research on the natural environment sustainability. Scannel and Gifford (2010) have synthesized various definitions of the concept into the three dimensions of personprocess-place organizing framework. The personal dimensions and principles of social sustainability refer to its individually or collectively determined meanings. The psychological dimension includes the affective, cognitive, and behavioral components of sustainability. The place dimension emphasizes the place characteristics of sustainability, including spatial level, specificity, and the prominence of social or physical elements (Scannel \& Gifford, 2010).

Reviewing exciting definitions of social sustainability- suggested within various built environment disciplines, revealed that there are common characteristics in these definitions. For this study, various definitions suggested by Polese and Stren (2000), Chiu (2003), McKenzie (2004), Bradley and Lee (2005), Litting and Griessler (2005), Magis and Shinn (2009), Colantonio (2010), Karuppannan and Sivam (2011), Bacon et al., (2012), Woodcraft et al., (2011), Laguna (2014) have been reviewed and three main referred characteristics of social sustainability have been extracted (Ghahramanpouri et al., 2015) and summarized in Table 1.

Table 1: General ideas in definitions of social sustainability.

\begin{tabular}{ll}
\hline Idea or Objective & Definition \\
\hline Future focus & $\begin{array}{l}\text { Social sustainability is concerned the ability of human being in every } \\
\text { generations to not merely survive, but also to thrive. }\end{array}$ \\
\hline $\begin{array}{l}\text { Satisfaction of } \\
\text { needs }\end{array}$ & $\begin{array}{l}\text { A condition where an extended set of basic needs are met for all residents } \\
\text { of the community, regardless of their race, ethnicity, age, religion, gender, } \\
\text { socioeconomic status and/or level of ability in the highest possible level of } \\
\text { social inclusion and participation in community life is promoted. }\end{array}$ \\
\hline $\begin{array}{l}\text { Socially cohesive } \\
\text { and physically } \\
\text { integrated urban } \\
\text { unit }\end{array}$ & $\begin{array}{l}\text { It describes the extent to which a neighborhood can support individual and } \\
\text { collective well-being of society. Social sustainability combines design of the } \\
\text { physical environment with a focus on how people can live and use the } \\
\text { spaces, relate to each other and function as a whole community. It is } \\
\text { enhanced by a development which provides the right infrastructure to } \\
\text { support a strong social and cultural life, opportunities for people to get } \\
\text { involved, and scope for the place and the community to evolve. }\end{array}$ \\
\hline
\end{tabular}




\section{Indices of Social Sustainability}

\subsection{Positive Physical and Social Indices}

Among different items influencing the degree of social sustainability, factors like accessibility, legibility, vitality, memory, diversity, comfort are considered as the key urban design attributes that define a successful place. It is claimed that the success of urban places is influenced by the ability of these places to accommodate human activity effectively (Jacobs, 1961). For instance in residential environments, open spaces that host various personal and group activities for the young through to the elderly, are of foremost importance in increasing social sustainability. Comfort and safety are also recognized as indispensable indexes for social attachment in urban neighborhoods (Hidalgo \& Hernandez, 2001). Other factors like duration of residence, number of relatives in a place and ownership of the house, seasonal celebrations, continued physical personalization, social cohesion and control have been discussed in different fields.

\subsection{Negative Physical and Social Indices}

Changes to the physical setting, types of uses and street activities may consequently omission of what is precious and meaningful to the community usually lead to negative impact on social sustainability, particularly for those who have a long-term attachment to the area. Other factors like lack of meaning in places, lack of sense of place and identity, little authentic connection to local landscapes, ecosystems, history, culture are also among important negative indices.

Besides, increased levels of crime lead to lower social sustainability, and gradual loss of the public realm erodes the memories of a place and diminishes the sense of belonging and attachment. Decreased community-based activities and increased immigration results in loss of sustainability of inhabitants to their environment (Brown et al, 2003). In most circumstances, increasing social sustainability means more effort is made by residents to preserve the physical qualities of the areas and physical protection of the inhabitants and their public property. In sustainable neighborhoods and districts, with social control and public attention to the environment, more investment is dedicated to maintenance and restoration. With high levels of sustainability to their property, inhabitants would will to remain in the place despite hygienic or safety problems of the area. The overall impacts of the both positive and negative indices can be summarize in Table 2.

Table 2: Effective indices of social sustainability.

\begin{tabular}{lll}
\hline $\begin{array}{l}\text { Index } \\
\text { Consequence }\end{array}$ & $\begin{array}{l}\text { Influence } \\
\text { Domain }\end{array}$ & Index \\
\hline Positive & Physical & $\begin{array}{l}\text { Physical sustainability, Functional sustainability, Unique } \\
\text { characteristics, } \\
\text { Accommodating activities, Comfort, Open and outdoor spaces, } \\
\text { Safety and security, Accessibility, Vitality and diversity, Legibility }\end{array}$ \\
\hline Positive & Social & $\begin{array}{l}\text { Duration of residence, Number of relatives, Ownership of the } \\
\text { home, Reputation of the area, Daily encounters and activities, } \\
\text { Physical personalization, Beliefs and religious identity, Collective } \\
\text { possessions and memories, Collective behaviors and interaction, } \\
\text { Social control and surveillance, Low fear of crime }\end{array}$ \\
\hline
\end{tabular}




\begin{tabular}{lll}
\hline Negative & Physical & $\begin{array}{l}\text { Unfit neighborhood, Change in physical setting, Change in land } \\
\text { or property uses, Changing activities, Lack of meaning and } \\
\text { identity, Formal and economic globalization, Standardization of } \\
\text { processes }\end{array}$ \\
\hline Negative & Social & $\begin{array}{l}\text { Cultural globalization, Crime growth, Weakening of identity, Lack } \\
\text { of social contributions and cooperation, High rate of immigration }\end{array}$ \\
\hline
\end{tabular}

Social sustainability results from the attachment to a place, and meaning and identity are the most obvious outcomes of social sustainability. Increasing social sustainability in residential environments retains personal and collective identity of inhabitants. Usually, sense of identity is accompanied by satisfaction and wellbeing leading to higher degree of public acceptability. Besides, social contributions, safety and sense of familiarity increase through a heightened sense of social sustainability (Brown et al, 2003). The best conditions for social sustainability occurs when people develop the sense of attachment toward not only their own home but also the neighborhood and the city simultaneously. In most cases, results of studies have shown that the feeling of sustainability is high in some scales but low in the others. Regarding research on social sustainability there are notable themes: Firstly, main indices of significant factors in social sustainability are the main activities and potentials formed in residential, commercial, recreational spaces etc. For instance, in a commercial area, the indices that increase social sustainability are those that influence the economic potential as well as accessibility. Secondly, people who are attached to a place are not necessarily proud of living there (Knez, 2005). Thirdly, there is not always a decisive outcome when measuring the relevant indices of social sustainability. The indices are relative, and they differ, even to the point of contrast from case to case.

Generally, it can be deduced that there are five main doctrines which are relevant to the urban society in countries like Iran that guide the evaluation of a local community whether to be socially sustainable or not. These five doctrines include social capital, environment, economy, political influences, and finally place-making. The related notions to each of the five doctrines are presented in the Table 3. Certainly, the relevant weight of each doctrine varies from one specific community to the other, thus, it is not possible to transform these measures into a quantitative approach or generalized method (El-Husseiny \& Kesseiba, 2012).

Table 3: Main Five Doctrines Guiding Socially Sustainable Communities (El-Husseiny \& Kesseiba, 2012).

\begin{tabular}{ll}
\hline Doctrine & Constituents \\
\hline Social Capital & - Social Participation, \\
& - Shared interests, \\
& - Social cohesion, \\
& - Common experiences and bonds \\
\hline Environment & - Environmental Quality, \\
& - Safe and healthy environment, \\
& - Protection of human health, \\
& - Protection of environment \\
\hline
\end{tabular}




\begin{tabular}{ll}
\hline Economy & - Economic security and growth, \\
& - Meeting local needs locally, \\
& - Creating local vibrant economy \\
\hline Policy & Empowerment and Governance, \\
& - Participation in decision making, \\
- Democracy, & - Accountability \\
\hline Place-making & - Sense of place, \\
& - Well designed public space, \\
& - Enhance place and space \\
\hline
\end{tabular}

\section{Methodology}

Regarding the above-mentioned aspects of social sustainability and mentioning current planning standards for residential neighborhoods in Tehran, it seems that these aspects shall be combined together to produce a socially sustainable neighborhood in every zone of the city and lead to a widely experienced improvement of local identity. The selected area includes residential neighborhoods in district 12 of Tehran municipality allowing us to study a mid-income social class that is relatively uniform and benefit from common services. A great number of inhabitants have been living in these neighborhoods for many years; there is an abundance of old buildings and different outdoor spaces which provides opportunities for social activities, all of which have been identified as contributory indices of social and physical social sustainability. Most part of outdoor and social spaces in the selected study area, are under government ownership, have natural surveillance, and enjoy regular use by the whole community living throughout the neighborhood.

Among the inhabitants of neighborhood, 312 inhabitants participated voluntarily in this study, two participants were eliminated because they had left too many unanswered questions. Therefore, the final sample of the survey was composed of 310 participants. Of the total samples, $58 \%$ were male and $42 \%$ female, and all participants lived in dwellings at the time the study was undertaken. Participants were selected from all parts of the neighborhood. These groups showed no significant differences in their response to the questions. The average age of the participants was 29 years and had been living for an average of 12.6 years in that building, 15.1 years in the neighborhoods and 25.8 years in Tehran. Identification marks in the questionnaire of the survey covered sex, age, marital status, social class, homeownership, duration of residence in the building, neighborhood, and city and finally the number of people in each building. The influence domain of sustainability had two levels of social and physical, and three scales of building, neighborhood and city. To differentiate between physical and social dimensions of social sustainability, another two items were included on each scale in which the participant had either to leave the physical or the social environment. We asked the participants what they would feel if the people they lived with moved (in three levels of social sustainability to house/neighborhood/city), as well as what they would feel if they moved with the same people (physical sustainability to house, neighborhood and city). 
Replies range from 1 (I would be truly sad to move) to 4 (I prefer to move). On the second part, we asked the individuals to identify main indices that are crucial to them within the study scales of dwelling, neighborhood and city. They could describe the indices they felt relevant to them, or they could choose the proposed indices on the questionnaires. The indices were based on the characteristics of the neighborhood, both socially and physically. In order to test whether there were differences between the sample subgroups, we carried out the same analysis but added age and sex. Then, age of the all participants was rearranged in four groups including 18-24, 25-34, 35-60 and over 60 s, to have a greater number of related and similar subjects in each condition.

\section{Results}

The main objective of this research was to identify the indices that affect social sustainability, and compare the degree of this sustainability from a cross-section of the places of residence and neighborhood. We calculated average scores for various dimensions of sustainability which are summarized in Table 4, showing the most positive and negative indices in developing overall attachment in dwelling and neighborhood scales.

Table 4: Effective indices on social sustainability regarding dwelling and neighborhood scales

\begin{tabular}{lllc}
\hline Scale & Value & Index & Mean score \\
\hline \multirow{4}{*}{ Dwelling } & & Tranquility & $50.62 \%$ \\
& \multirow{4}{*}{ Positive } & Safety & $29.13 \%$ \\
& & Central HVAC systems Dwelling size & $11.35 \%$ \\
& & Lack of maintenance & $8.90 \%$ \\
\hline \multirow{5}{*}{ Negative } & Overcrowding & $54.64 \%$ \\
& & Cultural tensions & $28.18 \%$ \\
& & Other indices & $9.28 \%$ \\
& & Open spaces & $7.20 \%$ \\
\hline & Positive & Service facilities & $45.38 \%$ \\
& & Daily encounters & $38.61 \%$ \\
& & Number of relatives & $10.60 \%$ \\
& & Lack of maintenance & $5.41 \%$ \\
\hline & Overcrowding & $36 \%$ \\
& \multirow{2}{*}{ Negative } & Cultural tensions & $26 \%$ \\
& & Lack of contribution & $18.70 \%$ \\
& & Accessibility problems & $9.42 \%$ \\
& & Crimes & $6.22 \%$ \\
& & $3.65 \%$ \\
\hline
\end{tabular}

Table 5 illustrates relevant information on overall degree of social attachment regarding the dwelling scale, neighborhood and city in different age groups. The mean sustainability scores vary regarding the scale as well as age group of participants. The participants of the survey in different groups are quite attached to their neighborhood, which is consonant with the findings and results of previous studies.

According to the findings of the survey, neighborhood sustainability is of higher importance than dwelling and city scale, while dwelling sustainability was more 
significant than city sustainability. The younger age groups showed higher scores on attachment to dwelling territory than they did on city scales. Sustainability of the intermediate groups to the city is significantly higher than their sustainability to the dwellings. The results revealed no significant differences between the oldest group regarding the feeling of social attachment to their dwelling territory and neighborhood but their social attachment to the city is less than the other age groups living in the same area. Besides, an inter-group comparative analysis of participants in the survey revealed that attachment becomes much more important and significant with age and length of residence (Table 5).

Table 5: Overall sense of attachment to dwelling territory, neighborhood and city in various age groups.

\begin{tabular}{cccc}
\hline Age Group & Dwelling & Neighborhood & City \\
\hline $18-24$ & $55 \%$ & $66 \%$ & $54 \%$ \\
\hline $25-34$ & $54 \%$ & $68 \%$ & $64 \%$ \\
\hline $35-60$ & $52 \%$ & $72 \%$ & $72 \%$ \\
\hline Over 60 & $100 \%$ & $100 \%$ & $95 \%$ \\
\hline
\end{tabular}

\section{Discussion and Conclusion}

In the selected residential neighborhoods, community sustainability is the most significant one, and the neighborhood play the most prominent role in people's sustainability to the place. As expected from results of previous studies, inhabitants with longer residence in the area and home owners showed a more positive indicators of social sustainability. Furthermore, residents with a higher stress of crime, cultural or ethnic tensions, less social cohesion or control also felt less overall social attachment to the area. Despite the socio-economic similarity of selected communities, residents of the neighborhoods would experience more positive aspects of social sustainability if there was greater proportion of home ownership in the neighborhood, and less fear of crime. Due to results of previous studies, we expected the dwelling building to play a more significant role in residential sustainability, but in this case, the community regarded the neighborhoods as the most influential factor in the sense of sustainability. Regarding the differences between subgroups in all cases, we found that women have greater social sustainability than men living in the same neighborhood. This result is in accordance with the findings of previous studies and surveys. Similarly, attachment to place increases with age, although which scale of attachment is the most significant one differs with age. For example, in younger groups of residents, the dwelling involves greater degree of social sustainability, while, intermediate age groups are attached to the city more, but older age groups usually show no differences between the attachment to dwelling territory or the neighborhood.

As discussed in other studies, social sustainability is emerging as an area of planning, design and practice all over the world. This topic has gained great attention among Iranian urban planners, policy makers and designer as well as architects and developers in recent years, and several original studies have focused on the diverse aspects of social sustainability in urban and architectural studies. While there is clearly a need for a more 
rigorous approach to definition and application of social sustainability, still much work is necessary to examine how the idea is deployed in urban planning and design practice, in particular, to understanding how the concept shall be translated by different actors and used as justification for decision making, planning, design, interventions and investments in the material and social features of residential neighborhoods and cities.

\section{Acknowledgement}

This paper was extracted from the masters' degree dissertation of Zahra Mohammadzadeh Neilagh in Department of Architecture, North Tehran Branch, Islamic Azad University.

\section{References}

Altman, I. \& Low, S. M. (1992). Place sustainability. New York: Plenum Press.

Asadpour, B. \& Moslemi Haghighi, M. (2017). Effects of architectural factors on social interactions in poetics centers, Iranian Online Journal of Urban Research, 2(1), 1-4.

Brown, B., Perkin, D., \& Brown, G. (2003). Place sustainability in a revitalizing neighborhood: individual and block levels of analysis. Journal of Environmental Psychology, 23, 259-271.

El-Husseinya, M. A. \& Kesseibab, K. (2012). Challenges of social sustainability in neo-liberal Cairo: requestioning the role of public space, Procedia-Social and Behavioral Sciences, 68(2012), 790 - 803. doi: 10.1016/j.sbspro.2012.12.267.

Fromm, E. (1941). Escape from freedom. New York: Holt, Rinehart \& Winston.

Ghahramanpouri, A., Saifuddin Abdullah, A., Sedaghatnia, S. \& Lamit, H. (2015). Urban social sustainability contributing factors in Kuala Lampur streets, Procedia-Social and Behavioral Sciences, 201, 368 - 376.

Habibi, R. (2008). Subjective images and the meaning of place, Journal of Fine Arts, 35, 39-50.

Harun, N. Z., Zakariya, Kh., Mansor, M. \& Zakaria, Kh. (2014). Determining attributes of urban plaza for social sustainability, Procedia-Social and Behavioral Sciences, 153 (2014), 606 - 615.

Heidegger, M. (1962). Being and time (1927), New York: Harper \& Row, p.83.

Hidalgo, M. C. \& Hernandez, B. (2001). Place sustainability: conceptual and empirical questions, Journal of Environmental Psychology, 21, 273-281.

Jacobs, J. (1961). The death and life of great American cities, London: Peregrine Books.

Knez, I. (2005). Sustainability and identity as related to a place and its perceived climate. Journal of Environmental Psychology, 25, 207-218.

Montgomery, J. (1998). Making a city: urbanity, vitality and urban design. Journal of Urban Design, 3, $93-116$.

Raymond, C., Brown G. \& Weber, D. (2010). The measurement of place sustainability: personal, community, and environmental connections. Journal of Environmental Psychology, 30, 422-434.

Relph, E. (1976). Place and placelessness. London: Pion.

Roshan, F. \& Gorvanchi, A. (2017). Role of urban gardens and public spaces in meeting the cultural needs of adolescents and young adults, Iranian Online Journal of Urban Research, 2(1), 5-9.

Scannel, L. \& Gifford, R. (2010). Defining place sustainability: a tripartite organizing framework. Journal of Environmental Psychology, 30, 1-10.

Shahmoradi, F. \& Salehinia, M. (2016). Architectural impact of Yard in Jameh Mosque of Isfahan on behavior of visitors, Iranian Online Journal of Urban Research, 1(2), 1-5.

Stedman, R. C. (2003). Is it really just a social construction? The contribution of the physical environment to sense of place. Society \& Natural Resources, 16, 671-685. 